DOI: http://dx.doi.org/10.18309/anp.v1i49.1300

\title{
UMA PERSPECTIVA PRAGMÁTICA PARA O ESTUDO DOS LETRAMENTOS EM PERIFERIAS BRASILEIRAS
}

\section{A PRAGMATIC PERSPECTIVE FOR THE STUDY OF LITERACIES IN THE BRAZILIAN PERIPHERIES}

Daniel do Nascimento e Silva Universidade Federal de Santa Catarina, Florianópolis, Santa Catarina, Brasil

Resumo: Este texto apresenta as linhas gerais de uma perspectiva pragmática para a abordagem dos letramentos em periferias brasileiras. "Pragmático" aqui é entendido como aquilo que produz uma série de efeitos no mundo (conforme John L. Austin e Judith Butler) e também como prática que conjuga a tríade lei do sistema, rapidez da atividade e olhar reflexivo dos atores (conforme a abordagem da prática comunicativa de William Hanks). O artigo extrai as características de uma abordagem pragmática dos letramentos de trabalhos que problematizam e politizam a relação entre oralidade e escrita e que questionam o que conta como escrita numa sociedade. Retira essas características também de pesquisas etnolinguísticas com sistemas de escrita e de inscrição pictórica em grupos ameríndios, as quais sugerem não haver grupo humano sem um sistema convencional de grafismo. Em vista disso, a abordagem pragmática dos letramentos em periferias é, em última instância, uma forma de dialogar com pessoas que em alguma medida já escrevem, embora suas práticas não sejam legitimadas como escrita.

Palavras-chave: Letramentos; Pragmática; Periferia; Etnografia

Abstract: This paper presents the general lines of a pragmatic perspective for the study of
literacies in the Brazilian peripheries. "Pragmatic" here is understood as that which produces a
series of effects (in line with John L. Austin and Judith Butler) and as practice that articulates the
law of the system, the quick of activity and the reflexive gaze of actors (in line with the
communicative practice approach by William Hanks). The characterization of the perspective on
literacies draws from studies that critique and politicize the relation between speech and writing,
and that thereby question what counts as writing in a society. It also draws from ethnolinguistic
works on systems of writing and pictorial inscription in Amerindian societies. These studies
suggest that there is no human group without a conventional graphic system. Thus, the pragmatic
approach of literacies in the peripheries is ultimately a form of dialogue with people who, in
some way, already write, even if what they write is not legitimized as writing. Keywords: Literacies; Pragmatics; Periphery; Ethnography 


\section{INTRODUÇÃO}

Neste texto, apresento as linhas gerais de uma perspectiva pragmática para a abordagem dos letramentos em periferias brasileiras. A proposta a seguir é pragmática porque entende que os usos da leitura e da escrita produzem uma série de efeitos no mundo (em linha com as leituras de Kanavillil Rajagopalan e Judith Butler da obra do filósofo da linguagem John L. Austin) e que esses usos são, ao mesmo tempo, um tipo de prática (em linha com as análises que William Hanks e Inês Signorini fazem da linguagem situada). Como Pedro Garcez (neste volume), considero útil e relevante uma das definições pioneiras de letramento entre nós, proposta por Angela Kleiman (1995, p. 19): "podemos definir letramento como o conjunto de práticas sociais que usam a escrita, enquanto tecnologia e enquanto sistema simbólico, em contextos específicos, para objetivos específicos." Porém, como o presente dossiê não pressupõe a existência de um conceito unânime de letramento e, tendo em vista essa não-unificação, intenciona mapear diferentes perspectivas de trabalho e assim produzir conhecimento novo sobre o tema, pretendo situar a novidade desta proposta em torno da relevância dos significados "das práticas sociais que usam a escrita" para as periferias do Brasil.

Antes de avançar, talvez seja importante explicar minha ênfase na questão da leitura e da escrita nas periferias ${ }^{1}$. A produção acadêmica global em sociolinguística, antropologia linguística e linguística aplicada tem dado bastante atenção ultimamente ao conceito de escala (ver CARR; LEMPERT, 2016). O conceito é relevante para dar conta das dimensões, comparações, contrastes e hierarquizações envolvidos em nossa atividade de contextualização. Quando se fala em periferia, por exemplo, pressupõe-se a existência de espaços não-periféricos ou centrais. Aprendemos com o estruturalismo que o significado de ambos os termos, periferia e centro, se dá pela diferença que estabelecemos entre eles. Aprendemos ainda que não há nada essencial em "centro" e ou "periferia" que constitua seu significado; trata-se, ao contrário, de um processo formal, linguístico, de distinção. O interesse pelas escalas, porém, tem levado os teóricos e as teóricas do campo dos estudos de linguagem e sociedade a refletir sobre a atividade perspectiva envolvida no próprio ato de fazer ou reutilizar uma distinção como esta. Marylin Strathern define escala como: "a organização de perspectivas sobre objetos de conhecimento e investigação" (apud CARR; LEMPERT, 2016, p. 5). Assim, por exemplo, ao circunscrever um espaço social numa pesquisa acadêmica ou numa ação de formação de professores - digamos, um complexo de favelas - e ao tornar esse espaço um objeto de conhecimento, estou, nos termos de Strathern, organizando uma perspectiva sobre esse espaço, isto é, engajando-me numa atividade interessada, investida de poder e situada em disputas institucionais. A organização de uma escala sobre esse espaço confere a ele relevância, em condições e lutas institucionais específicas. Escalas são úteis para nos lembrar que diferenças são acompanhadas de hierarquias e disputas pelo poder encaixadas na ação de contextualizar.

Em minha experiência pessoal de ensino e pesquisa, tenho "escalado" - encontrado dimensões, medido, comparado, mas também subido e descido - a periferia de diferentes maneiras. Obtive um doutorado em linguística pela UNICAMP, com estágio na Universidade da Califórnia em Berkeley, ao pesquisar uma grande periferia brasileira, o Nordeste (ver SILVA, 2012). Interagindo com meus/minhas interlocutores/as na UNICAMP e na UC Berkeley, organizei diferentes perspectivas sobre os significados dessa periferia: tentei fazer sentido do

\footnotetext{
${ }^{1}$ Alguns exemplos de análises pragmáticas de letramentos no Brasil (que não necessariamente comungam de todas as características apontadas aqui) são: Rajagopalan (2005), Souza (2011), Maia (2017), Lopes, Silva, Facina, Calazans \& Tavares (2017).
} 
território da pobreza e da fome, tão frequentemente invocado em São Paulo; procurei entender as aspirações de um núcleo de Brasil moderno, que se constitui também ao se diferenciar do território assustador, fantasmagórico, cadavérico e esfomeado do nordeste brasileiro. Ao falar ou escrever sobre meu objeto de estudos para meus interlocutores, situacionalmente, produzia escalas sobre ele: dimensões, conexões e nuances dessa periferia iam se moldando nas interações. Em seguida, a partir de uma pesquisa de campo no Complexo do Alemão, RJ, sobre a qual falarei adiante, ficou evidente que "periferia" é um conceito relacional, plástico, ajustável, gradiente em uma palavra, escalar.

O preâmbulo acima me ajudará a delinear melhor a proposta do presente artigo. É conhecido, e relativamente datado e ultrapassado nas abordagens críticas dos letramentos, o debate sobre as supostas características intrínsecas de sociedades (tidas como) orais e sociedades letradas - nos termos da presente discussão, as primeiras seriam sociedades periféricas e as segundas, centrais. Walter Ong (2012 [1982]) e Jack Goody (1977) são dois expoentes da posição de que a introdução da escrita traria outras formas de cognição a sociedades vistas como orais. Ong (2012 [1982]), por exemplo, afirma literalmente que o "pensamento baseado na oralidade", comparado com o pensamento influenciado pela escrita, é "agregativo em vez de analítico", "redundante", "tradicionalista", "empático e participativo em vez de objetivamente distanciado", "situacional em vez de abstrato" (p. 36-57). Diversas críticas, calcadas em evidências empíricas das relações entre oralidade e letramento, tornaram essa tese datada (no Brasil, ver MARCUSCHI, 2001; SIGNORINI, 2001a). Mas eu gostaria de pontuar que, embora seja de certa forma consensual nas abordagens do letramento a posição de que não há características intrínsecas à escrita que a tornem inerentemente favorável ao pensamento analítico ou à abstração, ou mesmo que a oralidade tenha as características arroladas por Ong, a noção de "sociedades sem escrita" ou de grupos dentro de uma sociedade letrada "que não escrevem" está ainda inscrita na escala dos letramentos periféricos. Aliás, essa inscrição é um tanto invisibilizada nessa escala dos letramentos, dando-se a ver mais frequentemente em termos de efeitos do que em termos de uma formulação explícita. A abordagem pragmática procura tornar esse ponto cego visível. Dito de outro modo, a abordagem pragmática dos letramentos nas periferias está embasada justamente na inversão da dicotomia entre oralidade e escrita e no consequente reconhecimento de que, de um ponto de vista empírico, não há sociedades sem formas de inscrição gráfica, como desenhos, pinturas etc. (SEVERI, 2013). Entender que grupos periféricos, em alguma medida, já escrevem (ou minimamente possuem mecanismos de organizar a experiência graficamente) transforma o estudo e o ensino do letramento num modo de diálogo entre sujeitos que dominam (diferentemente) mecanismos de inscrição simbólica.

A proposta a seguir foi dividida em três partes. Na primeira, parto do trabalho de Signorini (2001b) com um grupo de estudantes de uma universidade de elite e aponto como uma abordagem prática ou pragmática tem contribuído para tornar visíveis processos de legitimação do que conta como escrita numa sociedade hierarquizada como a brasileira. Na segunda, elaboro sobre a experiência de socialização de um jovem favelado no campo da sociologia acadêmica, o que de certo modo inverte a ordem oral-escrita nesse tipo de profissão letrada. Na terceira, revisito trabalhos com escrita e sistemas de inscrição (imagens) em grupos indígenas americanos; revisito também a visão da escrituralidade do oral, de Derrida, de forma a apontar caminhos produtivos de estudo dos letramentos nas periferias. 


\section{A RELAÇÃo COMUNiCATIVA E POLÍTICA ENTRE FALAR E ESCREVER}

Dentro da perspectiva pragmática dos letramentos, a relação entre fala e escrita é, ao mesmo tempo, comunicativa e política. Politizar essa relação também significa visibilizar a escrituralidade do oral na escala periférica dos letramentos. Tomarei como exemplo de uma análise que conjuga prática comunicativa e política o trabalho de Signorini (2001b). A autora aborda o hibridismo de oralidade e escrita em textos produzidos por sujeitos da periferia. Sua análise enfoca principalmente os "graus variados de visibilidade" desses elementos híbridos "na comunicação social" (p. 99). Uma pergunta inicial que pesa para uma abordagem dos letramentos é: o que conta como escrita e como oralidade quando o que está em questão são as práticas de sujeitos periféricos?

A análise que Signorini faz das produções textuais nunca é somente "linguística". Assim, os momentos em que a autora faz uma descrição da pragmática textual das produções em questão são seguidos de uma problematização política de sua contínua recontextualização. $\mathrm{O}$ enunciado a seguir exemplifica o primeiro tipo de descrição (pragmático-textual): "O traço mais saliente desse tipo de escrita é a presença de elementos associados à língua falada, ou, como se costuma dizer na escola, à 'interferência' do oral no escrito" (SIGNORINI, 2001b, p. 98). Já o próximo enunciado instancia o que estou chamando de problematização política: "Sobretudo quando a língua falada em questão não é socialmente prestigiada, essa escrita costuma ser percebida como não existente enquanto objeto significativo, como não atuante em nenhum contexto comunicativo." (SIGNORINI, 2001b, p. 98).

Eu diria então que uma proposta pragmática dos estudos dos letramentos nas periferias conjuga análises pragmáticas e sociolinguísticas das práticas e eventos de letramentos com uma análise política da produção de visibilidades e invisibilidades sobre a escrita ${ }^{2}$. Por exemplo, a autora propõe uma discussão sobre a recontextualização de uma carta originalmente produzida por um jovem indígena de 17 anos, endereçada a um alto funcionário da FUNAI e que exibe as mixagens em questão. Os comentários sobre a carta - uma atividade de recontextualização desse artefato - foram gerados numa atividade proposta a graduandos do $8^{\circ}$ período de Letras da UNICAMP. A diagramação pouco usual da carta, do ponto de vista da escrita escolarizada ou legítima, juntamente com o hibridismo de modelos textuais de "conversas informais com alguém conhecido e das tarefas escolares de reprodução de modelos de frases e textos da escrita padrão" (SIGNORINI, 2001b, p. 102) produzem efeitos de leitura bastante diversos em dois/duas graduandos/as, cujos comentários escritos são trazidos para a discussão de Signorini. Reproduzo os comentários:

a) Por tratar-se de uma carta a um chefe, não deveria conter tantas oralidades. É um texto completamente desconexado e possui informações desnecessárias. A menos que o receptor valorize pessoas que sabem fazer negócios.

b) Não há um domínio pleno da escrita, da norma, mas o emissor usa bons recursos na persuasão de seu interlocutor. O pequeno negociante tenta pelo menos considerar o que o Dr. Flávio pensaria sobre seu pedido.

\footnotetext{
${ }^{2}$ A perspectiva teórica para o estudo de eventos e práticas de letramento adotada aqui segue os trabalhos de Street (1993, 2001), Kleiman (1995) e Kleiman \& Assis (2016).
} 
Parece ser um garoto esperto que se vê numa boa empreitada perto desse seu Dr. Flávio. O garoto não quer perder esse negócio não (SIGNORINI, 2001b, p. 102-103).

O comentário (a) é típico das cenas de avaliação da escrita em que predomina uma ideologia linguística de texto escrito como espelhamento das capacidades cognitivas do autor e como instância de tipos de enunciados canônicos e cultos, articulados sequencialmente numa ordem auto evidente de continuidade e progressão tópica e de marcação de nexos e relações transtópicos também tidos como auto evidentes. A análise pragmática desse comentário feita por Signorini, além de enfatizar a avaliação reflexiva do/a graduando/a sobre a argumentação - vista como repleta de "oralidades" e de "pirueta[s] desnecessária[s], incompatível[is] com o jogo de cena convencionalmente mais sóbrio da carta comercial" (SIGNORINI, 2001b, p. 104) -, é articulada a uma análise política que evidencia o "tipo de pessoa no mundo"3 iconizado pelo comentário:

O efeito de descompasso assim detectado entre formas e funções na textualização é também associado à falta de uma ordenação lógica das informações no texto (...), tida como sintomática de um descompasso funcional cognitivo: grandes dificuldades de expressão na linguagem verbal. A mensagem inadequada, ou defeituosa é, portanto, um sinal, ou um índice, de uma dificuldade do sujeito com a lógica de comunicação verbal, não só com a escrita. A convicção subjacente é a de que a construção do texto é uma atividade analítica complexa e consciente, na qual se dá uma estruturação lógica análoga à das chamadas funções mentais superiores. (SIGNORINI, 2001b, p. 104, itálico no original)

A análise de Signorini conjuga, portanto, o que se faz com a linguagem e o que se fala do que se faz com a linguagem, ou seja, articula pragmática e metapragmática. No excerto acima, a articulação é mais propriamente com o que se fala daqueles que usam a linguagem - nessa cena de interlocução, o jovem indígena é visto como incapaz lógico, ser contradistinto daqueles que escrevem "bem".

Aproximando a abordagem pragmática dos letramentos e a abordagem prática proposta por Hanks (1996, p. 11), tem-se que uma análise da prática comunicativa - como a de Signorini é composta pela convergência de três elementos: "a lei do sistema, a rapidez da atividade e o olhar reflexivo do valor". Para o autor, uma prática comunicativa é constituída por uma relação triádica entre a "língua como um sistema semiformal, as atividades comunicativas como processos semiestruturados e as avaliações dos atores sobre ambas" (HANKS, 1996, p. 230, ênfase minha). Tais como os comentários metapragmáticos analisados por Signorini, essas avaliações são ideológicas, "no sentido de incorporarem valores mais amplos, crenças e (às vezes) atitudes autolegitimadoras" (HANKS, 1996, p. 230). Essas avaliações são ainda "metalinguísticas ou metadiscursivas, porque incidem diretamente sobre a língua ou o discurso, servindo para fixar seu significado."(ibidem). Finalmente, “embora essas avaliações metapragmáticas pareçam pouco acuradas do ponto de vista da forma ou dos aspectos objetivos da atividade" - como o comentário (a) - e "embora elas envolvam desreconhecimento [outra noção de Bourdieu], trata-se de fatos sociais como quaisquer outros" (HANKS, 1996, p. 230). Nossas avaliações metapragmáticas são parte central da forma como organizamos nossas ações e entendemos as ações dos outros.

\footnotetext{
${ }^{3}$ Raymond Williams propõe que "uma definição de língua é sempre, implícita ou explicitamente, uma definição de seres humanos no mundo" (apud WOOLARD, 1998, p. 21).
} 
A articulação desse princípio pode ser evidenciada também na análise do comentário (b), posicionado pela autora como "representativo das avaliações mais favoráveis (menos numerosas)" da carta indígena - uma prática letrada periférica - que serviu como mote para os comentários da turma. Na avaliação do/a estudante (b), o escrevente indígena emerge como "pequeno negociante esperto". Essa imagem de pessoa com "domínio dos meios de que dispõe para a consecução de seus objetivos" - ou um "garoto [que] não quer perder o negócio não" - é articulada a uma compreensão sociolinguística das normas de domínio do indígena, que "regem práticas locais (em contraposição a universais) de sedução e persuasão de um interlocutor específico" (SIGNORINI, 2001b, p. 105). A abordagem prática/pragmática de Signorini, portanto, situa a tríade forma-atividade-reflexividade num vocabulário político sobre a escrita:

\begin{abstract}
Nesse sentido é que se pode dizer, como o autor do comentário (b), que no/pelo uso da escrita vinculada a essas práticas, o autor da carta se constitui como um garoto esperto, e não como um indivíduo com grandes dificuldades em se expressar (comentário (a)), reconfigurando assim a lógica de uma relação ideológica e política dada entre a ordem do discurso e a ordem das condições (RANCIERE, 1995), segundo a qual quem tem domínio pleno da escrita, ou seja, da norma, tem condições e está autorizado na esfera pública; quem não tem esse domínio, não tem condições e não está autorizado (SIGNORINI, 2001b, p. 105).
\end{abstract}

Como aponta a autora no excerto acima, essas avaliações sobre a língua não são aleatórias; ao contrário, são produzidas e estruturadas dentro de um regime ordenado no qual a atividade linguística ganha valor e validade. Foucault (1996 [1970]) deu a esse regime o nome de ordem do discurso. Nas palavras do autor, a ordem do discurso diz respeito ao fato de que "em toda sociedade a produção do discurso é ao mesmo tempo controlada, selecionada, organizada e redistribuída por certo número de procedimentos que têm por função conjurar seus poderes e perigos, dominar seu acontecimento aleatório, esquivar sua pesada e temível materialidade" (FOUCAULT, 1996, p. 8-9). Contemporaneamente, autores como Silverstein (2003) e Blommaert (2010) têm falado em ordem indexical, assim chamando a atenção, à la Foucault, para o fato de que o sentido social ou indexical dos enunciados ocorre "em padrões oferecendo percepções de similaridade e estabilidade que podem ser percebidos como 'tipos' de prática semiótica" (BLOMMAERT, 2010, p. 37). Habitar esses regimes ordenados não é algo homogêneo. Relatarei a seguir um encontro na pesquisa no Complexo do Alemão que, de certo modo, marca uma inscrição alternativa no que poderíamos chamar de ordem dos letramentos hegemônicos.

\title{
3. EM VEZ DE FALA, ESCRITA: A TRAJETÓRIA DE ALAN BRUM PINHEIRO
}

Em 2012, iniciei uma pesquisa etnográfica, junto com Adriana Facina e Adriana Carvalho Lopes, sobre práticas de letramentos no Complexo do Alemão, um conjunto de doze favelas na Zona Norte do Rio de Janeiro. Entrevistamos, naquele ano, Alan Brum Pinheiro, um dos coordenadores do Instituto Raízes em Movimento, uma ONG local que congrega ações de cidadania, memória e resistência à violência. Após visitarmos com ele a estação Alemão do hoje desativado teleférico que interligava cinco favelas do Complexo, almoçarmos num restaurante próximo à estação, repleto de policiais da Unidade de Polícia Pacificadora do Alemão que também comiam ali, e caminharmos até o Instituto Raízes, conversamos longamente com ele 
sobre sua trajetória de vida. Nascido no Complexo do Alemão, no final da década de 1960, Alan morou em outros bairros da cidade até fixar residência novamente no Alemão, no final dos anos 1990.

À época, em face da escassez de políticas públicas de inclusão dos jovens periféricos como as ações afirmativas e a expansão do ensino técnico e superior que ganhariam força na segunda metade da década de 2000 -, Alan não teve acesso imediato ao ensino superior. Segundo ele: "não tinha bolsa, não tinha cotas, não tinha nada nessa época"4. Ele tocava então a vida, tentando finalizar um ensino médio técnico em comunicação e sobreviver por meio de diferentes trabalhos: ajudante de garçom, garçom, profissional de marketing, operador de máquina de xerox. E é nesta última ocupação que se dá o início de uma socialização um tanto inusitada no campo da sociologia. Em 1996, Alan é contratado para trabalhar no serviço de xerox da Fundação Getúlio Vargas (FGV). Essa instituição abriga um reconhecido curso de ciências sociais, cujo corpo docente se vincula ao Centro de Pesquisas e Documentação de História Contemporânea do Brasil (CPDOC). O jovem favelado era encarregado de tirar cópias de textos utilizados pelos pesquisadores nas disciplinas de sociologia, além dos materiais selecionados pelas várias pessoas que se dirigem ao CPDOC para fazer pesquisas. Alan nos contou que sempre gostara de ler. Ele passou a se sentir atraído por aqueles textos, muitos dos quais abordavam questões caras à sua experiência vivida no Alemão, como vida urbana, desigualdade e violência no Rio de Janeiro. Antes de tirar a xerox dos materiais, ele costumava parar para ler aqueles que o interessavam. Não raro, as cópias não ficavam prontas porque ele tinha se ocupado de ler os textos em vez de copiá-los. Até que algumas reclamações do atraso nas cópias passaram a chegar à administração da FGV e Alan foi, pela primeira vez na vida, demitido.

No entanto, de forma indireta, Alan foi se "aproximando das Ciências Sociais por ali". Meu ponto é que esses passos iniciais da trajetória de Alan como sociólogo - hoje ele é mestrando em Sociologia na UERJ, orientado por Luiz Antonio Machado da Silva, um dos grandes expoentes nos estudos sobre favela e violência urbana no Brasil - invertem os passos iniciais esperados na formação de um sujeito na área. Grosso modo, neófitos no campo da sociologia ingressam num curso de graduação e, inicialmente participando de debates por meio da oralidade (obviamente, também por formas híbridas e multimodais), passam então a ler textos da área. Mas Alan inverte o processo e inicia sua inscrição na sociologia "sozinho", pela leitura". Em suas palavras: "Ali que eu fui conhecer, eu não sabia o que era Ciências Sociais, né, e as pesquisas. A xerox do material, a xerox das teses, coisa e tal, e eu começava a ler e o pessoal vinha buscar o material, o material não tava pronto, porque eu tava lendo." Demitido, Alan resolve prestar vestibular para sociologia e, em 1997, ingressa na UERJ.

Embora seja difícil separar, no relato acima, eventos que se deram em torno da leituraescrita (i.e., eventos de letramento) e eventos puramente orais (em que medida a conversa dos/as pesquisadores o estimulou a ler?), a trajetória de Alan na sociologia é o inverso do caminho esperado na formação de um sociólogo. Morador de um território que até em discursos bemintencionados é visto como carente, marcado pela ausência de Estado, de segurança, de leitura e de escrita, Alan inicia sua inserção no campo teórico da sociologia por uma via improvável nos termos de discursos que posicionam a favela como espaço da ausência. Alan prova que a favela é

\footnotetext{
${ }^{4}$ As citações à fala de Alan foram extraídas de entrevista com Patrícia Lanes, realizada em 2015, e gentilmente cedidas pela pesquisadora e por Alan Pinheiro. O entrevistado concordou com a publicização de seu depoimento. A pesquisa está aprovada no Comitê de Pesquisa do CCE/UFSC, Processo: 20173314.

${ }^{5}$ De um ponto de vista dialógico, não há atividade plenamente solitária, na medida que em sociedade os sujeitos estão em relação. Os efeitos das relações sociais se fazem sentir quando realizamos atividades sozinhos.
} 
também um espaço da presença e da abundância cultural. Ele se torna então o primeiro de sua família a ingressar na universidade. Alan escritura sua socialização inicial em sociologia, tendo provavelmente incorporado aos seus eventos clandestinos de leitura elementos das conversas dos/das pesquisadores/as sobre os textos e sua própria experiência vivida na favela e em outros bairros do Rio de Janeiro. É desnecessário dizer que aquela leitura clandestina inicial foi performativa: produziu uma série de efeitos como a fundamentação de seu trabalho de militância no território, além de suas atividades atuais de pesquisa e consorciação de pesquisadores no Complexo do Alemão.

O que esse caso empírico pode nos dizer a respeito das práticas de letramento nas periferias? Abaixo, pretendo articular uma nuance da socialização inicial de Alan na sociologia com pesquisas sobre escrita e formas de inscrição (como desenhos) nos povos nativos das Américas e com a posição de Derrida sobre a "escrituralidade do oral".

\section{A LIÇÃO DAS PERIFERIAS PARA OS LETRAMENTOS}

Parto de três evidências empíricas para retomar, pragmaticamente, a pergunta inicial: o que conta como oralidade e escrita nas periferias?

A primeira é na verdade um conjunto de evidências vindas do trabalho de Carlo Severi (2013; 2017). Baseado em sua extensa pesquisa sobre os índios Kuna do Panamá e em estudos sobre imagens das mais diversas tradições indígenas, o antropólogo tem argumentado que, se por um lado é possível falar em sociedades que não possuem escrita, por outro lado é impossível falar de um grupo humano sequer que não possua um sistema de imagens. As traduções que esses povos fazem de signos verbais a outros sistemas de signos - como imagens, artefatos (que muitas vezes têm imagens inscritas, como cestos e vasos), gestos rituais ou músicas - revelam uma incrível sistematicidade e convencionalidade nessas formas de tradução, o que fornece a esses indígenas possibilidades comumente associadas exclusivamente à escrita, como a transmissão de mensagens para interlocutores não presentes e para gerações futuras. Severi aponta que a tradição do pensamento filosófico linguístico costuma argumentar que esse tipo de tradução - chamada por Jakobson (1969) de transmutação ou tradução intersemiótica, pelo fato de ela traduzir uma mensagem de um sistema de signos a outro - seria "apenas um comentário verbal sobre imagens visuais ou acústicas", ou que "por conta de se apoiar em códigos heterogêneos de sinais (verbais e não verbais), dificilmente ela pode[ria] gerar uma forma de conhecimento", ou ainda que "uma vez que um código icônico não é um meio de comunicação comparável à escrita, nenhuma tradição cultural ou transmissão de conhecimento poderia ser construído sobre ele" (SEVERI, 2017, p. 227). A posição de Severi, ao contrário, é de que a atividade pictórica entre indígenas revela um sofisticado processo convencional e ritual de comunicação e pensamento - justamente algumas das características atribuídas aos usos da escrita -, e que as imagens não podem ser reduzidas a meros "adornos". O trecho a seguir é significativo:

Nós, antropólogos, não podemos nos permitir esta atitude. A etnografia das tradições 'orais' geralmente nos confronta não apenas com sistemas de interpretação consistentes, efetivos e duradouros de signos verbais por meio de imagens - por exemplo, a escrita pictórica dos Indígenas das Grandes Planícies, os quipus andinos ou a pictografia nahuatl [...] Em muitas culturas ameríndias, por exemplo, verificamos que interpretações de signos pertencentes a um sistema não verbal podem ser percebidas por meio de signos pertencentes a outro sistema não verbal. Por exemplo, uma afirmação ou uma noção, geralmente expressas por meio de palavras, podem ser primeiro "traduzidas" em imagens e, posteriormente, ser 'traduzidas' (dever-se-ia dizer 'transmutadas') em 
música ou gestos ritualísticos. (SEVERI, 2017, p. 227-228)

Embora não seja a mesma coisa que a escrita alfabética, a pictografia indígena é capaz de convencionalmente comunicar alguns tipos de ações, nomes próprios, seres humanos e nãohumanos, qualidades, transformações - o que as línguas naturais fazem a partir de formas gramaticais variadas. Essas imagens facilitam a memorização de mitos, sua transmissão e interpretação, participando assim da estruturação da sociedade. Esses grupos podem não escrever, mas tratá-los como grupos "orais", sem sistemas convencionais "consistentes, efetivos e duradouros" de imagens ou de outras formas não orais de representação, é sintoma de grafocêntrismo.

A segunda evidência vem do trabalho de Lynn Mario Menezes de Souza (2001). Em um projeto de alfabetização e formação de professores que se transformou em espaço etnográfico para sua pesquisa com os Kaxinawá do Brasil, o autor aponta que esses indígenas transformaram a escrita alfabética que aprenderam. Em vez de ser transformado pela escrita - como se lê no discurso teleológico de algumas vertentes dos estudos dos letramentos -, esse grupo indígena "se apropri[ou] e transform[ou] a própria escrita, adaptando-a e moldando-a à imagem de sua própria cultura" (SOUZA, 2001, p. 187). Menezes de Souza observa que o grande índice dessa transformação é o fato de a escrita dos "Kaxinawá, tanto em português quanto em Kaxinawá, [vir] acompanhada por uma profusão de textos visuais, na forma de desenhos mono ou policromáticos" (2001, p. 176). Assim como Severi, Menezes de Souza se dedica a interpretar a convencionalidade e os gêneros dos desenhos indígenas - formas simbólicas rituais, duradouras e sistemáticas por meio das quais esses grupos articulam sua cosmologia.

A terceira evidência vem do trabalho de William Hanks (2015) sobre a história colonial de catequização e alfabetização dos índios Maia da região mexicana de Yucatán. Hanks explica que a introdução da escrita alfabética foi fundamental para o trabalho colonial de conversão dos indígenas. Ele argumenta que esse processo de conversão tem uma importante dimensão sociolinguística, à qual o autor chama de reducción - isto é, a produção de um regime ordenado que realizou a "conversão do espaço, ação e língua indígenas" (HANKS, 2015, p. 652). Auxiliados pelos indígenas, os missionários franciscanos "escreveram as gramáticas e dicionários, criaram os catecismos ensinados aos neófitos maia e selecionaram e treinaram jovens maias talentosos na posição de escribas" (HANKS, 2015, p. 651). Esse sistema de conversão e ensino da escrita foi fundamental para a criação da ordem cristã nas cidades, e os escribas tiveram um papel central na produção do "corpus de documentos cartoriais que temos hoje".

Essa observação histórica aponta que, para além da adaptação à escrita e da apropriação desse sistema às práticas locais, os indígenas também "expropriaram a escrita alfabética para seus próprios fins" (HANKS, 2015, p. 652). O autor demonstra que, ao se "apropriarem da ortografia, [os maias] a utilizaram não apenas para contar sua própria versão dos eventos mas também para tomar posse de textos centrais das missões" (HANKS, 2015, p. 666). Para a presente reflexão, a característica mais importante das práticas apócrifas geradas nesse processo de conversão colonial por meio da escrita é o fato de os indígenas não terem sentido "a introdução da escrita alfabética em medida alguma [como algo] novo ou exótico". (HANKS, 2015) Os maias escreveram sobre a vinda dos espanhóis e sobre a nova ordem introduzida, "mas a escrita alfabética não foi nunca mencionada" por eles (HANKS, 2015, p. 669). A explicação que Hanks dá para isso é que a escrita não era novidade para os maias pela simples razão de que eles já escreviam! Nas palavras do autor: "Se a escrita alfabética é uma tecnologia revolucionária, por que ela pareceu tão comum? A razão é que os maias já eram letrados, tendo desenvolvido seu letramento por quinze séculos" (HANKS, 2015, p. 670). Os maias já haviam desenvolvido uma 
escrita glífica havia vários séculos: “o script logossilábico do corpus glífico, os códices, o papel revestido no qual eles foram escritos, a profissionalização do escriba, e mesmo a associação entre escrita e religião já ocorriam nessa sociedade." (HANKS, 2015) A diferença, diz Hanks, foi que a escrita alfabética trouxe uma ortografia "mais flexível, universal e seletiva". Algo semelhante ocorreu no contato entre romanos e árabes, tendo os primeiros adotado o sistema numérico dos segundos, tornando mais prática a realização de operações matemáticas. Ninguém diria, no entanto, que os romanos não sabiam contar ou fazer operações lógicas com números antes desse empréstimo. Mais importante ainda, entre os maias, o corpus hieroglífico evidencia que "as operações mentais-chave requeridas para o engajamento com o letramento alfabético já estavam presentes no letramento glífico" (HANKS, 2015, p. 670).

Os três casos acima apontam para o fato - que não é novo entre nós - de que o letramento (alfabético, ocidental) não traz embutidas capacidades imanentes de raciocínio lógico, sistematização da experiência ou permanência gráfica; os processos de tradução intersemiótica abordados por Severi, a escrita multimodal analisada por Menezes de Souza e a técnica hieroglífica enfatizada por Hanks atestam trajetórias complexas, sofisticadas e sistemáticas de usos da escrita e de outros sistemas de inscrição já presentes em grupos periféricos das Américas. Além desses casos, a inscrição que Alan faz no regime de letramentos acadêmicos da sociologia, clandestinamente transformando modos orais de aquisição de conhecimento (p.ex., no gênero aula) em modos escritos (pela leitura clandestina de textos do CPDOC), mostra que a ordem dos letramentos hegemônicos é habitável de formas alternativas.

A meu ver, a noção de escrituralidade do oral (e da experiência em geral), desenvolvida por Derrida ao longo de sua prolífica filosofia é bastante afim à abordagem pragmática dos letramentos em periferias que venho delineando. Para resumir um conceito que não é simples (e que certamente me tomaria muito mais páginas do que disponho aqui), gostaria de apontar que a questão da escrita e de sua relação com o oral ocupa um lugar central na filosofia de Derrida (ver RAJAGOPALAN, 2005). A proposta de investigar o caráter escritural do oral tem a ver com sua própria atividade filosófica de descontruir a metafísica - o que não significa tentar destruí-la, uma vez que filosofar é, para ele, habitar a metafísica. Desde Platão, o oral tem sido posicionado como o sopro primeiro, que constitui a imediatez da experiência e dá autenticidade ao dito (já que os interlocutores, numa cena de fala prototípica, estariam presentes e autenticariam a sinceridade de seu dizer). Tanto é assim que o principal mentor dos filósofos gregos, Sócrates, jamais escreveu. Derrida observa esse movimento de pureza como plena presença em diversas empreitadas metafísicas: na política, na filosofia, na antropologia, na linguística. E contrariamente à visão platônica da imediatez e autenticidade da fala - que estaria na base do fonocentrismo da linguística e do privilégio da experiência autêntica dos povos "sem escrita" da antropologia Derrida (1976) argumenta que a própria oralidade é constituída também por características comumente atribuídas à escrita, como espaçamento, descontextualização e adiamento. $\mathrm{O}$ modo como segmentamos a/s língua/s que falamos e nossa inabilidade de segmentar - isto é, de encontrar intervalos entre palavras e outras unidades - línguas que não conhecemos é um exemplo de espaçamento (visual, grafemático) que guia nossa atividade na fala. E na medida em que uma unidade de fala pode sempre ser adiada, descontextualizada e desidentificada de sua origem - por exemplo, uma fofoca permite que seu "autor" descontextualize um evento, apague sua própria autoria como emissor e assim adie a autenticidade da emissão -, a dimensão espacial da fala é também uma "temporização" (MORRIS, 2007, p. 359).

Nos termos de Derrida (1991), qualquer grupo humano que utilize a oralidade já escreve em alguma medida, já que a experiência humana é ela própria constituída por meio de marcas 
grafemáticas e diferenciais. Em vista da posição teórica desse autor e do conjunto de evidências empíricas que trouxe aqui (de Signorini a Hanks, passando pelo meu próprio campo) para situar uma abordagem pragmática dos letramentos em periferias, gostaria de apontar que uma última característica dessa abordagem é: uma vez que o encontro intercultural (entre um alfabetizador e um jovem da periferia, por exemplo) é sempre um encontro entre pessoas que já escrevem, o que está em questão nesses eventos é, antes de tudo, um diálogo entre práticas letradas. Dito de outro modo, abordar letramentos em periferias é adentrar numa ordem discursiva ou indexical que organiza (mas não completamente determina) interações entre sujeitos diferentes, hierarquias, relações de poder e de saber; e que orienta sobretudo o que conta como "escrito" e "oral" (e a forma como essas práticas são hierarquizadas). Imaginar que o estudo e a pedagogia do letramento em periferias são, em certa medida, o estudo ou o ensino de pessoas que já escrevem pode, em última instância, abrir espaços e condições na agenda do próprio estudo para atribuir valor e validade a trajetórias de letramento, a inscrições legítimas e clandestinas no regime da escrita e, principalmente, a modos complexos, sofisticados e alternativos de escrever, mas que são invisibilizados como "apenas" oralidade.

\section{Referências}

BLOMMAERT, Jan. The Sociolinguistics of Globalization. Cambridge: Cambridge University Press, 2010.

CARR, E.; LEMPERT, M., (Orgs). Scale: Discourse and Dimensions of Social Life. Berkeley: University of California Press, 2016.

DERRIDA, Jacques. Of Grammatology. Tradução de Gayatri Chakravorty Spivak. Baltimore: The Johns Hopkins University Press, 1976.

DERRIDA, Jacques. "Assinatura acontecimento contexto". In: DERRIDA, J. Margens da filosofia. Tradução de Joaquim Torres Costa; António M. Magalhães. Campinas: Papirus, 1991.

FOUCAULT, Michel. A ordem do discurso. São Paulo: Loyola, 1996 [1970].

GOODY, Jack. The Domestication of the Savage Mind. New York: Cambridge Univ. Press, 1970.

HANKS, William. Language and Communicative Practices. Boulder: Westview Press, 1996.

HANKS, William. Alphabetic literacy and colonial process in Yucatán. Ethnohistory, [S.L]. v. 62, n. 3, 2015, p. 651-674.

JAKOBSON, Roman. "Aspectos linguísticos da tradução”. In: JAKOBSON, R. Linguística e comunicação. Tradução de Izidoro Blikstein e José Paulo Paes. São Paulo: Cultrix, 1969.

KLEIMAN, Angela B. "Introdução: Modelos de letramento e as práticas de alfabetização na escola". In: KLEIMAN, Angela B. (Org.). Os significados do letramento: uma nova perspectiva sobre a prática social da escrita. Campinas: Mercado de Letras, p. 15-61, 1995. 
KLEIMAN, Angela; ASSIS, Juliana. (Orgs). Significados e ressignificações do letramento: desdobramentos de uma perspectiva sociocultural sobre a escrita. Campinas: Mercado de Letras, 2016.

LOPES, Adriana; SILVA, Daniel; FACINA, Adriana; CALAZANS, Rafael; TAVARES, Janaina. Desregulamentando dicotomias: transletamentos, sobrevivências, nascimentos. Trabalhos em Linguística Aplicada, Campinas, v. 56, n. 3, p. 753-780, 2017.

MAIA, Junot. Fogos digitais: Letramentos de sobrevivência no Complexo do Alemão/RJ, 2017. Tese (Doutorado em Linguística Aplicada) - Instituto de Estudos da Linguagem, Universidade Estadual de Campinas, Campinas.

MARCUSCHI, Luiz A. Da fala para a escrita: atividades de retextualização. São Paulo: Cortez, 2001.

MENEZES DE SOUZA, Lynn Mario. "Para uma ecologia da escrita indígena: A escrita multimodal kaxinawá". In: SIGNORINI, Inês (Org.). Investigando a relação oral/escrito e as teorias do letramento. Campinas: Mercado de Letras, 2001, p. 167-192.

MORRIS, Rosalin. Legacies of Derrida: Anthropology. Annual Review of Anthropology, [S.L]. v. 36, p. 355-389, 2007.

ONG, Walter. Orality and literacy: the technologizing of the world. London: Routledge, 2012 [1982].

RAJAGOPALAN, Kanavillil. A escrituralidade do oral: a desconstrução derrideana e suas implicações para o ensino, 2005. Disponível em: http://www.leffa.pro.br/tela4/Textos/Textos/Anais/SENALE_IV/IV_SENALE/Kanavillil_Rajago palan.htm Acesso: 27 maio 2019.

SEVERI, Carlo. "O espaço quimérico. Percepção e projeção nos atos do olhar." In: SEVERI, Carlo; ELS, Lagrou (Orgs.) Quimeras em diálogo: grafismo e figuração na arte indígena. Rio de Janeiro: 7 Letras, p. 25-65, 2013.

SEVERI, Carlo. Seres transmutantes: Uma proposta para uma antropologia do pensamento. Trad. Felipe Neis Araújo. Ilha, [S.L], v. 19, n. 1, p. 217-262, 2017

SIGNORINI, Inês. Investigando a relação oral/escrito e as teorias do letramento. Campinas: Mercado de Letras, 2001a.

SIGNORINI, Inês. "Construindo com a escrita 'outras cenas de fala"”. In: SIGNORINI, Inês (Org.) Investigando a relação oral/escrito e as teorias do letramento. Campinas: Mercado de Letras, p. 97-134, 2001B. 
SILVA, Daniel. Pragmática da violência: o Nordeste na mídia brasileira. Rio de Janeiro: Faperj/7 Letras, 2012.

SILVERSTEIN, Michael. Indexical order and the dialetics of sociolinguistic life. Language and Communication, [S.L], v. 23, p. 193-229, 2003.

SOUZA, Ana Lúcia Silva. Letramentos de reexistência: poesia, grafite, música, dança: hip-hop. São Paulo: Parábola, 2011.

STREET, Brian. Cross-cultural approaches to literacy. Cambridge: Cambridge University Press, 1993.

STREET, Brian. Literacy and development. Ethnographic perspectives. Londres: Routledge, 2001.

WOOLARD, Kathryn. "Introduction: Language ideology as a field of inquiry". In: SCHIEFFELIN, B. et al. (Orgs.) Language ideologies: Practice and theory. Oxford: Oxford University Press, 1998.

Daniel do Nascimento e Silva danielnss@gmail.com

Recebido em: 15 de Julho de 2019

Aceito em: 12 de Agosto de 2019

Publicado em: Setembro de 2019 